\title{
Role of the Subunits of the Energy-Transducing Adenosine Triphosphatase from Micrococcus lysodeikticus Membranes studied by Proteolytic Digestion and Immunological Approaches
}

\author{
Faustino MOLLINEDO,* Vicente LARRAGA,* F. Javier COLL† and Emilio MUÑOZ* \\ * Sección Bioquímica de Membranas, Instituto de Inmunología y Biología Microbiana, \\ Velázquez 144, Madrid-6, Spain, and †Servicio de Inmunología, Centro Especial Santiago Ramón y Cajal, \\ Madrid-34, Spain
}

(Received 25 July 1979)

\begin{abstract}
An energy-transducing adenosine triphosphatase (ATPase, EC 3.6.1.3) that contains an extra polypeptide $(\delta)$ as well as three intrinsic subunits $(\alpha, \beta, \gamma)$ was purified from Micrococcus lysodeikticus membranes. The apparent subunit stoichiometry of this soluble ATPase complex is $\alpha_{3} \beta_{3} \gamma \delta$. The functional role of the subunits was studied by correlating subunit sensitivity to trypsin and effect of antibodies raised against holo-ATPase and its $\alpha, \beta$ and $\gamma$ subunits with changes in ATPase activity and ATPase rebinding to membranes. A form of the ATPase with the subunit proportions $1.67(\alpha): 3.00(\beta): 0.17(\gamma)$ was isolated after trypsin treatment of purified ATPase. This form has more than twice the specific activity of native enzyme. Other forms with less relative proportion of $\alpha$ subunits and absence of $\gamma$ subunit are not active. Of the antisera to subunits, only anti- $(\beta$ subunit) serum shows a slight inhibitory effect on ATPase activity, but its combination with either anti-( $\alpha$-subunit $)$ or anti- $(\gamma$-subunit $)$ serum increases the effect. The results suggest that $\beta$ subunit is required for full ATPase activity, although a minor proportion of $\alpha$ and perhaps $\gamma$ subunit(s) is also required, probably to impart an active conformation to the protein. The additional polypeptide not hitherto described in Micrococcus lysodeikticus ATPase had a molecular weight of 20000 and was found to be involved in ATPase binding to membranes. This 20000 -dalton component can be equated with the $\delta$ subunit of other energy-transducing ATPases and its association with the $(\alpha, \beta, \gamma) M$. lysodeikticus ATPase complex appears to be dependent on bivalent cations. The present results do not preclude the possibility that the $\gamma$ subunit also plays a role in ATPase binding, in which, however, the major subunits do not seem to play a role.
\end{abstract}

The ATPases (EC 3.6.1.3) from energy-transducing membrane systems play a key role in cell energy transduction. These enzymes, named $F_{1}$ factors, can be easily solubilized from their membrane complexes and subsequently purified by conventional procedures (Senior, 1973; Pedersen, 1975; Kozlov \& Skulachev, 1977). They have been characterized as oligomeric proteins made up of three to five subunits, depending on their origins. Mitochondrial and chloroplast $F_{1}$ factor contain five subunits designated as $\alpha, \beta, \gamma, \delta$ and $\varepsilon$, with respective molecular weights of $55000,50000,35000,15000$ and 12000 (Penefsky, 1974; Pedersen, 1975; Nel-

Abbreviations used: $F_{1}$ factor, the water-soluble portion of the ATPase-ATP synthetase complex, or watersoluble coupling factor; $\mathrm{BF}_{1}$ factor, bacterial $\mathrm{F}_{1}$ factor; SDS, sodium dodecyl sulphate. son, 1976) on the basis of their relative mobilities in SDS/polyacrylamide-gel electrophoresis. Bacterial $\mathrm{F}_{1}$ factors from Escherichia coli (Vogel \& Steinhart, 1976), Streptococcus faecalis (Abrams et al., 1976a) and the thermophile bacterium PS $_{3}$ (Yoshida et al., 1977) are also made up of five subunits, thus appearing structurally similar to the $F_{1}$ ATPases from mitochondria and chloroplasts. However, two to three subunits have been identified in purified $\mathrm{BF}_{1}$ factors from aerobic Gram-positive cocci and bacilli; $\alpha, \beta$ and $\gamma$ subunits have been found in Micrococcus lysodeikticus $\mathrm{BF}_{1}$ factor (Andreu et al., 1973; Andreu \& Muñoz, 1975; Carreira et al., 1977), and only the two major subunits ( $\alpha$ and $\beta$ ) in ATPases of Bacillus megaterium and Bacillus subtilis (Mirsky \& Barlow, 1973; Serrahima-Zieger \& Monteil, 1978). 
In order to understand the molecular basis of energy transduction in the different systems, a comparison of the roles of each subunit in different ATPases is needed. The functions of the subunits have been studied by experiments with antibodies against each of them in the case of $F_{1}$ factor from chloroplasts (Nelson et al., 1973) and E. coli (Kanner et al., 1975), by controlled proteolytic digestion of chloroplast $F_{1}$ factor (Deters et al., 1975) and bacterial ATPases (Nelson et al., 1974; Bragg \& Hou, 1975; Abrams et al., 1976b; Höckel et al., 1976) and by reassociation of dissociated subunits (Yoshida et al., 1975, 1977; Vogel \& Steinhart, 1976; Smith \& Sternweis, 1975). From these studies, no integrated point of view has yet emerged. On the one hand, it has been concluded that subunits $\alpha$ plus $\beta$ are required for catalytic activity (Deters et al., 1975; Höckel et al., 1976), but in other cases such complexes showed no activity (Yoshida et al., 1977). The minor subunits $(\gamma, \delta$ and $\varepsilon$ ) have been involved in ATPase binding to the membranes (Smith \& Sternweis, 1975; Sternweis, 1978); it has been shown that a segment of $\alpha$ subunits of $S$. faecalis ATPase plays a critical role in the attachment of the enzyme to the membrane (Abrams et al., 1976b). Functional roles for $\gamma, \delta$ and $\varepsilon$ subunits have also been suggested (Nelson et al., 1973; Nelson \& Karny, 1976; Larson \& Smith, 1977; Yoshida et al., 1977).

In view of this complexity, the analysis of the subunit function of ATPases differing in the number of their subunits appears to be of great significance for a definition of the structure-function relationships in energy-transducing proteins. In this paper we describe the degradation of subunits of $M$. lysodeikticus ATPase by proteolytic enzymes, correlating it with loss of enzyme activity and ability to rebind to the membranes, as well as the effect of antibodies raised against whole ATPases and their three main subunits $(\alpha, \beta$ and $\gamma$ ) on these activities. ATPase forms with different subunit patterns have also been used as tools to determine the role of each subunit. An additional polypeptide component of $M$. lysodeikticus ATPase, of molecular weight 20000 , similar to that of the $\delta$ subunit, has been identified. This component seems to play a role in ATPase binding to the membrane.

\section{Materials and Methods}

\section{Preparation of soluble ATPase}

Micrococcus lysodeikticus strain A was grown and harvested as described (Andreu et al., 1973; Carreira et al., 1976a).

Membranes were prepared by osmotic shock of cell protoplasts (Muñoz et al., 1969), except that $10 \mathrm{~mm}$ - instead of $5 \mathrm{~mm}-\mathrm{MgCl}_{2}$ was used during protoplast formation. The membrane-bound ATP- ase was released into solution by suspension of carefully washed membranes for $10 \mathrm{~min}$ in $3 \mathrm{mM}^{-}$ Tris/ $\mathrm{HCl}(\mathrm{pH} 7.5)$ and centrifugation at $35000 \mathrm{~g}$ for $30 \mathrm{~min}$. During the first membrane washes a minimal concentration of $\mathrm{MgCl}_{2}(0.010-0.050 \mathrm{mM})$ was maintained. The depleted membranes were frozen as a pellet and kept to assay reattachment of the soluble purified ATPase.

The differences in the use of $\mathrm{MgCl}_{2}$ are relevant to explain the presence of a new polypeptide in purified M. lysodeikticus ATPase (see below).

\section{Purification of the ATPase and its subunits}

The crude soluble ATPase was purified by preparative polyacrylamide-gel electrophoresis as previously described (Andreu \& Muñoz, 1975). When analysed in SDS/7\%-acrylamide gels, freshly purified ATPase contained $\alpha, \beta$ and $\gamma$ subunits (Carreira et al., 1977) in the proportions $3: 3: 1$, together with variable amounts of $\beta^{\prime}$ polypeptide (Carreira et al., 1977; Andreu et al., 1973) and components of mobility 1.0 relative to that of Bromophenol Blue used as tracking dye. In 10\%-acrylamide gels, the components of relative mobility 1.0 were resolved into two components (see the Results section). In some instances, aged or repeatedly thawed and frozen ATPase preparations, which showed overlapping of $\alpha$ and $\beta$ subunits in 7\%acrylamide/SDS gels (Nieto et al., 1975), were used.

ATPase subunits $(\alpha, \beta$ and $\gamma$ ) were isolated as random-coil polypeptides by preparative gel electrophoresis of purified ATPase in the presence of $8 \mathrm{M}$ urea, required to dissociate the enzyme fully (Andreu \& Muñoz, 1975; Andreu et al., 1976).

Analytical gel electrophoresis in non-dissociating and dissociating conditions was carried out at pH $8.5 \pm 0.2$ as reported (Andreu et al., 1973). Gels of $7 \%$ acrylamide $/ 0.18 \% N N^{\prime}$-methylenebisacrylamide or $10 \%$ acrylamide $/ 0.28 \% N N^{\prime}$-methylenebisacrylamide were used. Electrophoreses were run at room temperature, first at $2 \mathrm{~mA} /$ column $(20 \mathrm{~min})$ and then at $5 \mathrm{~mA} /$ column $(2 \mathrm{~h})$.

In SDS/polyacrylamide-gel electrophoresis, gels and buffer contained $0.1 \%$ SDS and samples were pretreated with a detergent:protein ratio of $10: 1$ $(\mathrm{w} / \mathrm{w})$ at $85^{\circ} \mathrm{C}$ for $5 \mathrm{~min}$. In urea/polyacrylamide-gel electrophoresis, gels and upper buffer contained $8 \mathrm{M}$ urea/ $1 \mathrm{~mm}$-dithiothreitol, whereas the lower chamber did not contain urea. Samples were treated with $10 \mathrm{M}$-urea / $5 \mathrm{~mm}$-dithiothreitol before electrophoresis. Solutions of urea were freshly prepared before each use to avoid carbamoylation of proteins (Stark et al., 1960).

Gels were stained with either Coomassie Brilliant Blue R250 (Fairbanks et al., 1971) or Coomassie Brilliant Blue G-250 (Dietzel et al., 1972) and scanned at $575 \mathrm{~nm}$ in a Gilford 2400 spectrophotometer equipped with a $2410 S$ linear transport. 


\section{Preparation of antisera}

Antibodies were raised against purified ATPase from $M$. lysodeikticus membranes judged to be more than $95 \%$ homogeneous by polyacrylamide-gel electrophoresis. Pure enzyme $(0.4 \mathrm{mg})$ was incorporated in Freund's complete adjuvant to a final volume of $1 \mathrm{ml}$ and injected subcutaneously to rabbits. The rabbits were given weekly subcutaneous injections (each containing $0.4 \mathrm{mg}$ of pure ATPase) without adjuvant for a period of 3 weeks; 2 weeeks later, the rabbits were given a subcutaneous booster injection of ATPase $(0.4 \mathrm{mg})$. The rabbits were bled from an ear vein 1 week after the last injection. After irritation of the ear with xylene, the border vein of the ear was punctured with a needle and blood was collected. After clotting, serum was obtained, heated at $55^{\circ} \mathrm{C}$ for $30 \mathrm{~min}$ to inactivate complement (Brody \& Carlstrom, 1961) and stored without preservative at $-20^{\circ} \mathrm{C}$.

Antisera were also prepared against $\alpha, \beta$ and $\gamma$ subunits judged to be more than $92 \%$ homogeneous by gel electrophoresis in dissociating conditions. Rabbits were immunized intradermally into the footpad with a suspension of $300 \mu \mathrm{g}$ of each subunit in about $1 \mathrm{ml}$ of $30 \mathrm{~mm}$-Tris $/ \mathrm{HCl}$ (pH 7.5) mixed with an equal volume of Freund's complete adjuvant, followed by three weekly immunizations as above. After 1 week's rest, the animals were boosted subcutaneously with $200 \mu \mathrm{g}$ of each protein. Blood and serum were obtained as described above. Control sera were obtained from the blood of each rabbit before immunization.

\section{Immunodiffusion}

The Ouchterlony immunodiffusion reaction was carried out in agarose-coated plates as described by Campbell et al. (1964). The gels were prepared at $0.8 \%(\mathrm{w} / \mathrm{v})$ agarose in $30 \mathrm{~mm}-\mathrm{Tris} / \mathrm{HCl}(\mathrm{pH} 7.5)$. After overnight incubation at room temperature in a moisture chamber, precipitation patterns were examined directly.

\section{Immunoelectrophoresis}

This was performed on $10 \mathrm{~cm} \times 8 \mathrm{~cm}$ plates coated with agarose $(0.8 \mathrm{~cm}$ thick) (Clausen, 1969). The gels were prepared at $0.8 \%(\mathrm{w} / \mathrm{v})$ in $30 \mathrm{~mm}$-Tris $/ \mathrm{HCl}$ (pH 7.5). Samples containing about $25 \mu \mathrm{g}$ of protein were applied to wells $1.5 \mathrm{~mm}$ in diameter and subjected in $20 \mathrm{~mm}$-Tris/ $\mathrm{HCl}$ buffer ( $\mathrm{pH} \mathrm{7.5)} \mathrm{to} \mathrm{electro-}$ phoresis at $300 \mathrm{~V}$ for $2 \mathrm{~h}$ at $10^{\circ} \mathrm{C}$ in a LKB Multiphor apparatus. Whatman paper, soaked in buffer and laid on both ends of the plates, connected the buffer solution in the anode and cathode compartments with the agarose surface. After the electrophoretic run, a trough (well) was filled with antiserum and the plates were developed in a moisture chamber at room temperature for $24 \mathrm{~h}$.

\section{Analytical procedures}

ATPase activity was measured as described by Muñoz et al. $(1968 a, b)$. One unit of enzyme activity is defined as the amount able to liberate $1 \mu \mathrm{mol}$ of $\mathbf{P}_{1} / \mathrm{min}$ at $37^{\circ} \mathrm{C}$ under the experimental conditions described by Muñoz et al. (1968b). Protein was determined by the method of Lowry et al. (1951), with bovine serum albumin (Sigma Chemical Co., St. Louis, MO, U.S.A.) as standard.

\section{Inhibition of ATPase activity by antisera}

The ability of the antisera (to holo-ATPase and $\alpha$, $\beta$ and $\gamma$ subunits) to inhibit activity of ATPase was examined by preincubating the purified enzyme (0.06 unit) for $2 \mathrm{~h}$ at room temperature with increasing amounts of antisera in $600 \mu$ of $30 \mathrm{~mm}$-Tris $/ \mathrm{HCl}$ (pH 7.5). Portions $(150 \mu \mathrm{l})$ were withdrawn from these mixtures and assayed for ATPase activity with the following modification: the reaction was stopped by the addition of $0.2 \mathrm{ml}$ of $12.5 \%(\mathrm{w} / \mathrm{v})$ trichloroacetic acid and $P_{1}$ in the supernatant after centrifugation at $0^{\circ} \mathrm{C}(30 \mathrm{~min}$ at $37000 \mathrm{~g})$ was measured (Muñoz et al., 1968a,b).

\section{Re-insertion of ATPase into depleted membranes}

The procedure for measuring rebinding of ATPase to depleted membranes was as follows. Pure ATPase (0.12 unit) was mixed with depleted membranes $(500 \mu \mathrm{g}$ of protein) in $200 \mu \mathrm{l}$ of $30 \mathrm{~mm}$ Tris $/ \mathrm{HCl}$ ( $\mathrm{pH} 7.5) / 20 \mathrm{mM}-\mathrm{MgCl}_{2}$. The mixture was vigorously shaken for $5 \mathrm{~min}$, subsequently incubated for $15 \mathrm{~min}$ at $37^{\circ} \mathrm{C}$ and then centrifuged at $43000 \mathrm{~g}$ for $30 \mathrm{~min}$. The supernatant was recovered and the sediment was washed once with the same buffer and resuspended in $100 \mu \mathrm{l} 30 \mathrm{~mm}$-Tris/HCl buffer ( $\mathrm{pH}$ 7.5). ATPase activity was measured in sediment and supernatant. Samples without $\mathbf{M g}^{2+}$ served as controls of non-specific binding.

In other cases, re-insertion experiments were carried out with either ${ }^{3} \mathrm{H}$-labelled ATPase purified from cells grown in the presence of ${ }^{3} \mathrm{H}$-labelled amino acids (a gift from Dr. C. Muñoz) or ${ }^{125} \mathrm{I}$ labelled ATPase prepared by iodination with chloramine-T (a gift from Dr. N. Rubio). The procedure to perform rebinding was as above and ATPase bound to the sediment was measured by radioactivity counting (Larraga \& Muñoz, 1975).

\section{Trypsin treatment}

Samples of purified ATPase were incubated with trypsin at $37^{\circ} \mathrm{C}$ for different times in $200 \mu \mathrm{l}$ of $30 \mathrm{~mm}$-Tris/ $\mathrm{HCl}$ (pH 7.5) at trypsin/ATPase ratios of $1: 20$ to test the effect of the proteinase on ATPase subunits and enzyme activity, or $1: 15$ to correlate the effect of subunit modification with ATPase re-insertion into the membrane. To stop the action of trypsin, a 2-fold excess of soya-bean trypsin inhibitor was added. After these treatments, samples were 
analysed for ATPase activity or ability to rebind to the membranes. These properties were correlated with electrophoretic patterns in SDS or urea. Controls were run showing that the trypsin inhibitor did not influence the properties of the ATPase.

ATPase forms after trypsin treatment were isolated by micro-preparative gel electrophoresis. Trypsin-digested samples were run on $7 \%$ gels as described before. Every sample, containing about $40 \mu \mathrm{g}$ of protein, was loaded on a minimum of four different gels run at the same time. One of the gels was stained with Coomassie Blue G-250 for the rapid location of protein bands, whereas another was stained for the histochemical detection of ATPase (Muñoz et al., 1968b). Once the mobilities of the bands were measured, the proteins were eluted with $30 \mathrm{~mm}$-Tris $/ \mathrm{HCl}$ ( $\mathrm{pH} \mathrm{7.5)}$ from transverse slices of the corresponding zones and ATPase activity was measured, and the urea/- or SDS/-polyacrylamidegel patterns were analysed. ATPase samples untreated with trypsin were run under the same conditions and used as controls.

\section{Results}

Characterization of antisera against ATPase and its subunits

The antigenicity of the purified ATPase from Micrococcus lysodeikticus has been demonstrated in previous work (Muñoz et al., 1969; Whiteside \& Salton, 1970). The antigenicity of the isolated subunits of $M$. lysodeikticus ATPase is demonstrated for the first time in the present work. Moreover, this is, to our knowledge, the first demonstration that $F_{1}$ subunits isolated in urea are antigenic, because in previous studies with chloroplast and $E$. coli $F_{1}$ factor, SDS-subunit complexes were used as antigens (Nelson et al., 1973; Kanner et al., 1975).

Fig. 1 illustrates these immunological experiments. Fig. 1(a) shows the typical single precipitin line given by the ATPase antiserum when tested against the enzyme. The holo-ATPase reacted with antisera against isolated $\alpha$ and $\beta$ subunits (see Fig. $1 b$ ). The isolated $\alpha, \beta$ and $\gamma$ subunits reacted with anti-ATPase antiserum and with their respective antisera (see Figs. $1 c$ and $1 d$ ). This indicates that antigenic determinants of the subunits are expressed in whole ATPase. The antisera to subunits did not cross-react. It is worth noting that the differences in mobility towards the anode of the isolated $\alpha$ and $\beta$ subunits reflect their net negative charge (Andreu $e t$ al., 1976).

\section{Effect of antisera on ATPase activity of the purified enzyme.}

Fig. 2 illustrates the effect of the antibodies on the ATPase activity of purified enzyme. As shown in Fig. 2(a), the anti-(holo-ATPase) serum completely inhibited the activity, but of the anti-subunits sera, only anti-( $\beta$-subunit) serum showed a slight effect. The results obtained with combinations of different antibodies are shown in Fig. 2(b). The combination of anti-( $\beta$-subunit) serum with either anti- $(\alpha$-subunit) or anti-( $\gamma$-subunit) serum increased their effect to inhibit up to $50 \%$ of ATPase activity. However, the combination of anti-( $\alpha$-subunit $)$ and anti- $(\gamma$-subunit) serum did not show any effect. Combination of the three antibodies had no additional effect as compared with the combination of anti-( $\beta$-subunit) plus anti-( $\alpha$-subunit) or anti-( $\gamma$-subunit) serum. Similar effects of the antisera were observed on the activity of a trypsin-digested $(90 \mathrm{~min})$ ATPase (see below).

\section{Sensitivity of ATPase activity of the purified en- zyme to trypsin}

The effect of trypsin digestion on the ATPase activity of $M$. lysodeikticus ATPase is shown in Fig. 3. The activity did not change for the first $10 \mathrm{~min}$ incubation under these conditions. After this lag phase, a gradual decrease in activity to about $50 \%$ of the original value was observed over a period of about $50 \mathrm{~min}$. Incubation of the ATPase with trypsin for another period of $2 \mathrm{~h}$ did not substantially modify the $40 \%$ residual catalytic activity. This fact is interesting because it confirms the presence of a catalytic core in $M$. lysodeikticus ATPase that is resistant to trypsin digestion, as suggested from previous work with other active forms of the enzyme (Carreira et al., 1977). In this respect the difference from the ATPase of Streptococcus faecalis is selfevident (Abrams et al., 1975; Carreira et al., 1977). It is also noteworthy that by heating the ATPase in absence of proteinase (control), a slight activation of the enzyme was produced (results not shown).

In order to correlate the changes in activity with changes in the subunit pattern, ATPase samples were taken at different times during incubation with trypsin and electrophoresed in gels containing SDS or urea. The first system was used to obtain better resolution of the minor subunits, whereas the urea system gave better resolution between $\alpha$ and $\beta$ subunits. It is known from previous work that the overlapping of $\alpha$ and $\beta$ subunits on gels occurred rapidly after digestion of the ATPase with trypsin (Carreira et al., 1976b, 1977). Fig. 4(a) illustrates the experiments with SDS/polyacrylamide-gel electrophoresis showing that the digestion of the $\gamma$ subunit and the displacement of $\alpha$ subunit towards the mobility of the $\beta$ subunit are not concomitant with loss of ATPase activity (compare Figs. 3 and 4). Fig. 4(b) illustrates the scans obtained after urea/polyacrylamidegel electrophoresis, which clearly show the progressive destruction of the $\alpha$ subunit and the relative resistance of the $\beta$ subunit during digestion of ATPase with trypsin. In both sets of experiments it is possible to identify the presence of components 
(a)

(b)

(1)

(c)

$\alpha$

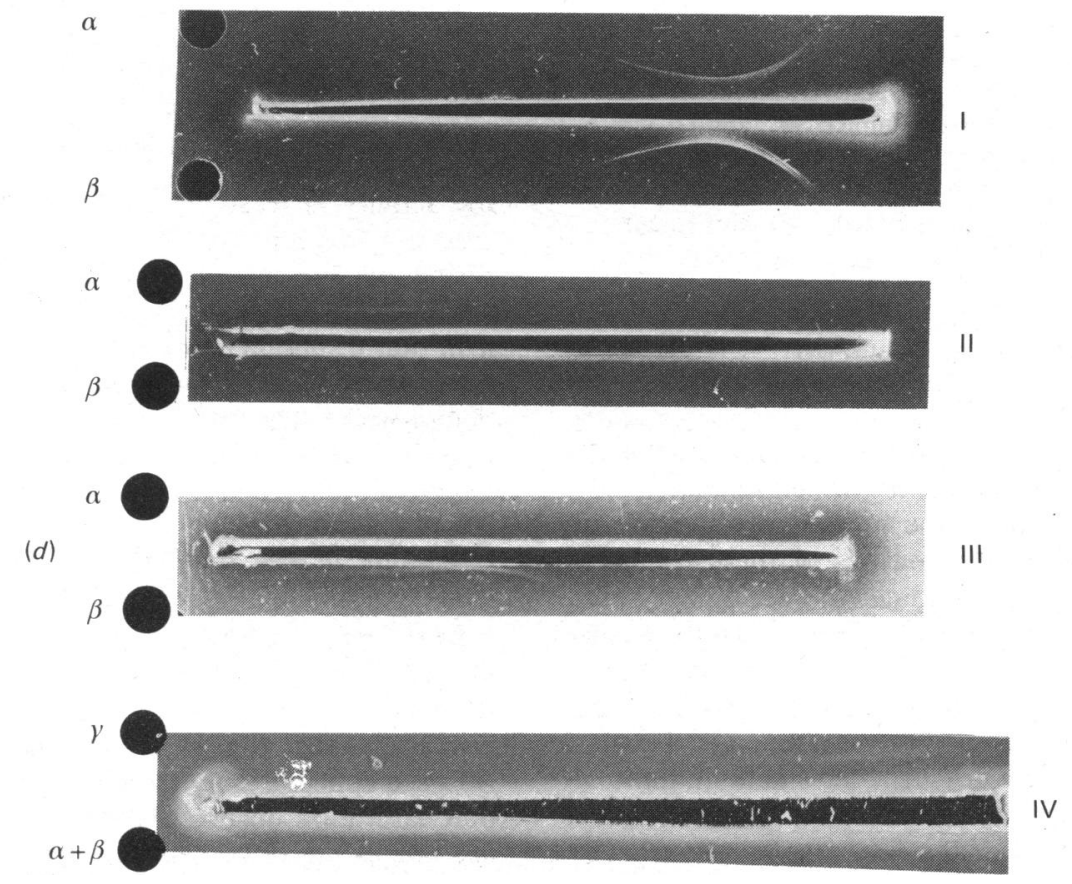

$\beta$

(1)

(6)

(5)

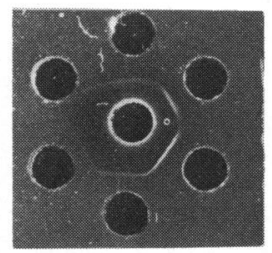

(4)
(3)

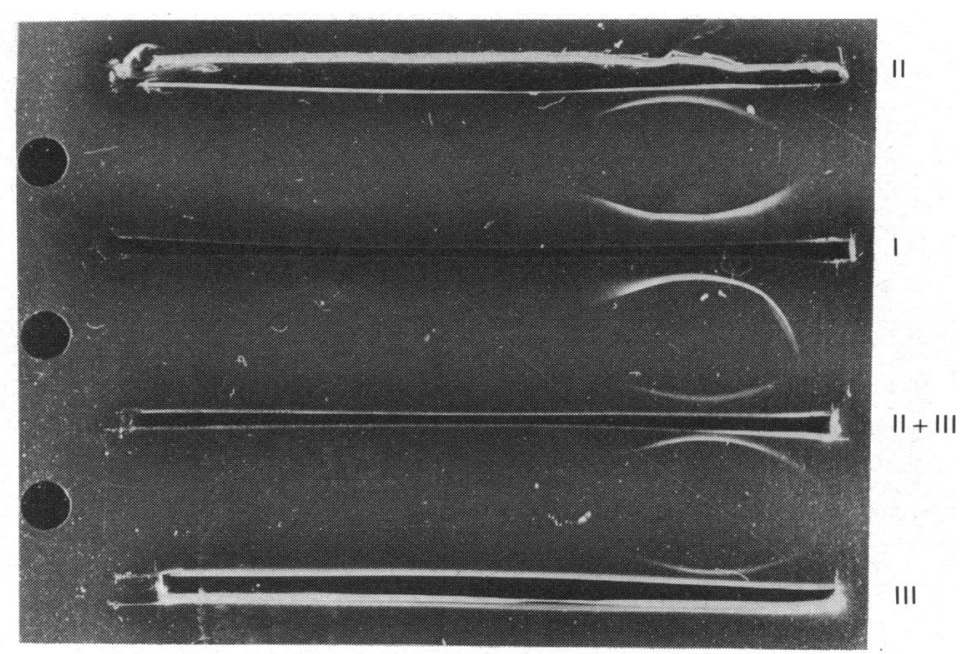

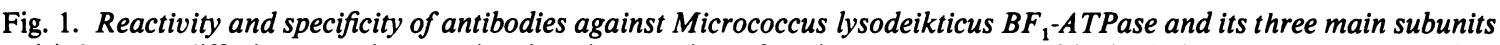
(a) Immunodiffusion experiments showing the reaction of anti-ATPase serum with the holoenzyme. Centre well, $35 \mu \mathrm{g}$ of purified ATPase. Outer wells, dilutions of anti-ATPase serum as follows: (1), undiluted; (2), 1/5; (3), 1/10; (4), 1/20; (5), 1/40; (6), 1/80. (b) Immunoelectrophoresis patterns of ATPase reaction with antisera against ATPase and its $\alpha$ and $\beta$ subunits. ATPase samples ( $20 \mu \mathrm{g}$ of protein) were in well (1); trough wells contained $150 \mu$ l of the following sera; I, anti-ATPase; II, anti-( $\alpha$-subunit); III, anti- $(\beta$-subunit); but in the mixture of anti- $(\alpha$-subunit $)$ and anti-( $\beta$-subunit) sera (II + III), $75 \mu \mathrm{l}$ of each serum was used. (c) Immunoelectrophoresis patterns of isolated $\alpha$ and $\beta$ subunits with anti-ATPase serum (I). Subunit samples contained $30 \mu \mathrm{g}$ of protein; trough wells contained $150 \mu \mathrm{l}$ of serum. (d) Immunoelectrophoresis patterns of isolated $\alpha, \beta$ and $\gamma$ subunits with their antisera (II, anti- $\alpha$; III, anti- $\beta$; IV, anti- $\gamma$ ). Subunit samples contained $30 \mu \mathrm{g}$ of protein, except in the mixtures of $\alpha$ and $\beta$ subunits (15 $\mu \mathrm{g}$ each); trough wells contained $150 \mu$ l of the respective sera. 


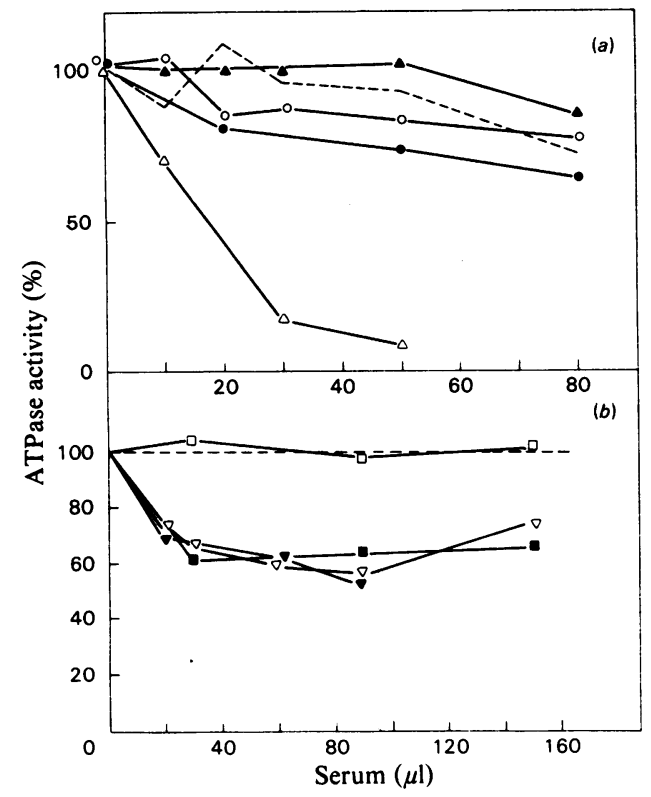

Fig. 2. Effect of antibodies (a) and their combination (b) on the ATPase activity of $M$. lysodeikticus $B F_{1}$ factor For experimental details see the Materials and Methods section. (a): -- - , control; antibodies: $\Delta$, anti-ATPase; $\Delta$, anti-( $\alpha$-subunit); $\boldsymbol{O}$, anti- $(\beta$-subunit); $O$, anti-( $\gamma$-subunit). (b): ---- , control; antibodies: $\square$, anti-( $\alpha$-subunit $)+$ anti- $(\gamma$-subunit $)$; anti-( $\alpha$-subunit $)+$ anti- $(\beta$-subunit $) ; \quad \nabla$, anti- $(\beta$-subunit $)+$ anti-( $\gamma$-subunit $) ; \quad \nabla$, anti-( $\alpha$-subunit $)+$ anti( $\beta$-subunit $)+$ anti-( $\gamma$-subunit). In these experiments, the sera were mixed in equal volumes to give the final amount indicated on the abscissa.

derived from modification of the subunits, such as $\beta^{\prime}$ (Fig. $4 a$ ) and $\mathrm{x}$ and $\mathrm{y}$ (Fig. $4 b$ ), which remain apparently unaltered through the process of digestion of ATPase. A quantitative analysis of these results is shown in Table 1; the residual ATPase activity correlates well with the percentage left of $\alpha+\beta$ subunits, in general, and with that of $\beta$ subunit, in particular. However, correlation does not exist between percentage of ATPase activity and amount of $\gamma$ subunit, although the requirement for small amounts of this subunit for activity cannot be ruled out.

In an attempt to define further the role of subunits in $M$. lysodeikticus ATPase activity, forms of the enzyme were isolated after its digestion with trypsin. Table 2 summarizes the properties of the two main components obtained after a $30 \mathrm{~min}$ digestion of ATPase with trypsin. Both forms have, as expected, higher mobilities than the control. The slowest one possesses twice the specific activity of native ATPase, whereas the fastest component is inactive. The comparison of the proportions of subunits between the forms allows us to conclude that the $\beta$ subunit is essential for activity, but it requires

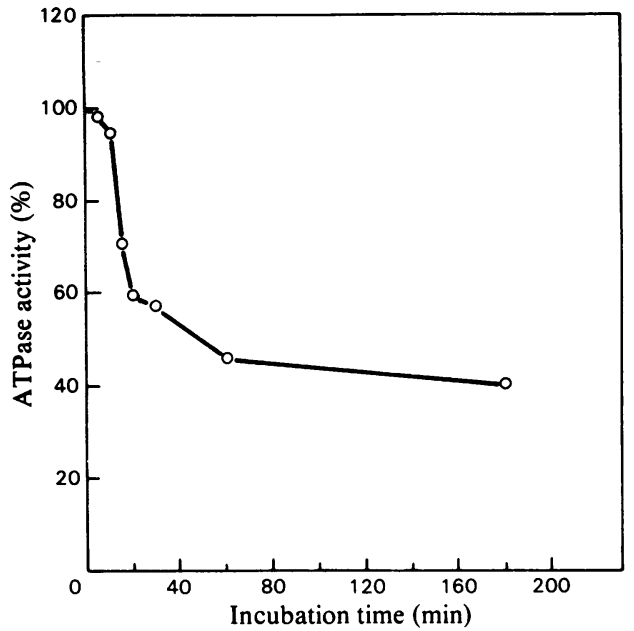

Fig. 3. Time course of the effect of trypsin on ATPase activity of $M$. lysodeikticus $B F_{1}$ factor

ATPase $(50 \mu \mathrm{g})$ was incubated with $2.5 \mu \mathrm{g}$ of trypsin as described in the Materials and Methods section. Samples corresponding to $5 \mu \mathrm{g}$ of ATPase were withdrawn at different intervals, trypsin inhibitor was added and the mixture was assayed for ATPase activity. For other details see the Materials and Methods section.

for activity at least one $\alpha$ subunit per three $\beta$ subunits to maintain or impart the appropriate conformation. On this ground, the role of $\gamma$ subunit in ATPase activity is very unlikely. These results confirm that $\beta$ subunit is not active by itself, as suggested from previous work (Andreu \& Muñoz, 1979), and demonstrate that component $\beta^{\prime}$, a product of the degradation of $\alpha$ subunit, is not involved in ATPase activity.

Rebinding of the ATPase to the membranes and effect of trypsin digestion and antisera on it

$\mathrm{Mg}^{2+}$ was essential for attachment of ATPase to the membrane. The omission of this bivalent cation from the assay completely abolished ATPase rebinding. Measurements of binding as a function of ATPase concentration (results not shown) indicated that saturation occurred at close to $100 \mu \mathrm{g}$ of ATPase bound $/ \mathrm{mg}$ of protein of depleted membranes, a value which is consistent with previous estimates of the amount of ATPase bound to native $M$. lysodeikticus membranes (Muñoz et al., 1969). Interestingly, these experiments also showed that, irrespective of the ATPase concentration used, about $50 \%$ of the ATPase molecules were efficient in rebinding. This suggested that half of the ATPase molecules were defective in the structural feature(s) that is (are) essential for binding (see the Discussion section). The possibility that this finding is the consequence of the heterogeneity in orientation of the membrane 
preparation seems unlikely, because such a result was even obtained when an excess of potential ATPase-binding sites may be available to ATPase

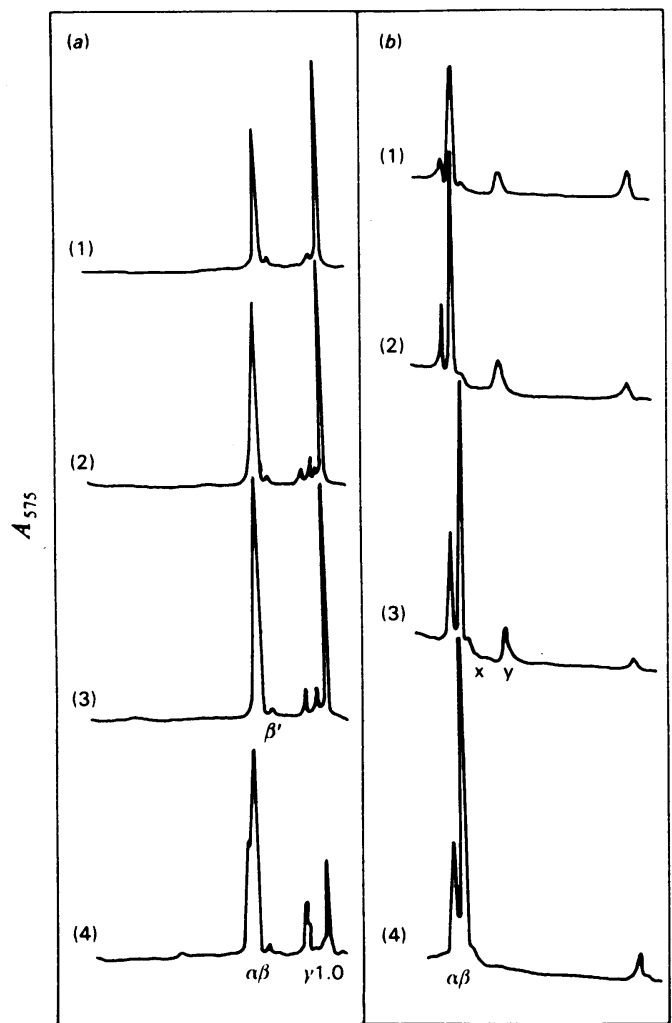

Fig. 4. Analysis by gel electrophoresis in SDS (a) and in $8 \mathrm{M}$-urea (b) of the subunit modification induced by trypsin in $M$. lysodeikticus $B F_{1}-A T P a s e$

ATPase samples $(70 \mu \mathrm{g})$ were incubated with tryp$\sin (3.5 \mu \mathrm{g})$ for different times: (1), $90 \mathrm{~min}$; (2), $30 \mathrm{~min}$; (3), $15 \mathrm{~min}$; (4), zero time. After processing as described in the Materials and Methods section, the samples were analysed by SDS/- or urea/-7\%acrylamide-gel electrophoresis. Migration was from left to right $(+)$. because of the very low concentration of ATPase used.

The ability of ATPase to rebind to depleted membranes was very sensitive to trypsin. It was therefore necessary to study the effect of the proteinase in shorter incubation times than those above to correlate structural modifications with the inability of the ATPase to reattach to membranes. Fig. 5 illustrates a typical experiment showing the effect of trypsin on ATPase binding and its correlation with SDS/polyacrylamide-gel-electrophoresis patterns. To increase the resolution of the electrophoretic system in the zone of low-molecular-weight components, $10 \%$ acrylamide gels were used. The components of relative mobility 1.0 in $7 \%$-acrylamide gels (see Fig. 4) were thus resolved (Fig. 5a) into two components: one of relative mobility 0.85 (mol.wt. 20000) and another of relative mobility 1.0 , which now represented a very small percentage of material. The former component has a molecular weight similar to that of the $\delta$ subunit in other $\mathrm{F}_{1}$-ATPases, and had not hitherto been reported in $M$. lysodeikticus ATPase (Andreu et al., 1973). Its association with the intrinsic $\mathrm{BF}_{1}$ molecule $(\alpha, \beta, \gamma$ subunits) seems to be dependent on the presence of $\mathrm{Mg}^{2+}$ in the membranes before solubilization of ATPase, and can be reversed by EDTA treatment of the purified ATPase (F. Mollinedo, unpublished work). In most preparations, one molecule of this $\delta$ subunit was found per molecule of the $\alpha_{3} \beta_{3} \gamma$ complex, considered previously as the intrinsic holo-ATPase (Andreu et al., 1973). After $5 \mathrm{~s}$ treatment with trypsin, the $\alpha$ subunit underwent a selective modification in its primary structure, being quantitatively transformed into an $\alpha^{\prime}$ form, which is distinguishable from the $\beta$ subunit in the $10 \%$-acrylamide system (Fig. $5 a$ ); this is another advantage as compared with the 7\%acrylamide/SDS-gel-electrophoresis system. On the other hand, about $50 \%$ of the component of relative mobility 0.85 was destroyed (Fig. $5 a$ and Table 3), which is consistent with a $50 \%$ decrease in the amount of ATPase bound to the membranes (Fig.

Table 1. Sensitivity to trypsin of the three main subunits $(\alpha, \beta$ and $\gamma)$ of Micrococcus lysodeikticus $B F_{1}$ factor in relation to ATPase activity

M. lysodeikticus ATPase samples (60 $\mu \mathrm{g}$ of protein) were treated with trypsin $(3 \mu \mathrm{g})$ for different times as described in the Materials and Methods section. Portions ( $5 \mu \mathrm{g}$ of ATPase) were assayed for ATPase activity and the rest of the samples were electrophoresed. After the analysis by SDS/- or urea/-polyacrylamide-gel electrophoresis (Fig. 4), the areas of the subunits were calculated from the densitometric scans of the gels stained with Coomassie Blue R-250.

Subunit area (\% of zero-time value)

Trypsin treatment (min)

\begin{tabular}{|c|c|c|c|c|c|}
\hline \multirow{7}{*}{ Electrophoresis } & \multicolumn{4}{|c|}{ Subunit area (\% of zero-time value) } & \multirow[b]{3}{*}{$\begin{array}{c}\text { ATPase activity } \\
(\%)\end{array}$} \\
\hline & \multirow[t]{6}{*}{$\ldots$} & Urea & \multicolumn{2}{|c|}{ SDS } & \\
\hline & & $\beta$ & $\alpha+\beta$ & $\gamma$ & \\
\hline & & 100 & 100 & 100 & 100 \\
\hline & & 77.8 & 71.5 & 31.1 & 70 \\
\hline & & 62.3 & 67.0 & 14.6 & 58 \\
\hline & & 35.6 & 33.5 & 6.8 & 46 \\
\hline
\end{tabular}

Vol. 186 
Table 2. Relationship between activity and subunit composition of ATPase forms isolated after trypsin digestion of Micrococcus lysodeikticus $B F_{1}$ factor

ATPase was treated with trypsin for $30 \mathrm{~min}$ (see Table 1) and the product of digestion was analysed and processed as described in the Materials and Methods section. The amount of protein corresponding to each band was calculated from the densitometric scans of gels run in non-dissociating conditions. For other details see the text and Table 1.

Enzyme form

Control ATPase

Active ATPase band

Non-active ATPase band
Relative mobility

$($ Bromophenol Blue $=1.00)$

0.28

0.34

0.59
Protein staining

(\% of total)

85.6

47.5

14.3
Specific activity

( $\mu \mathrm{mol} / \mathrm{min}$ per $\mathrm{mg}$ )

6

15

Subunit proportions

$\alpha: \beta: \beta^{\prime}: \gamma$

$2.72: 3.00: 0.03: 1.30$

$1.67: 3.00: 0.16: 0.17$

$0.43: 3.00: 5.38: 0.00$

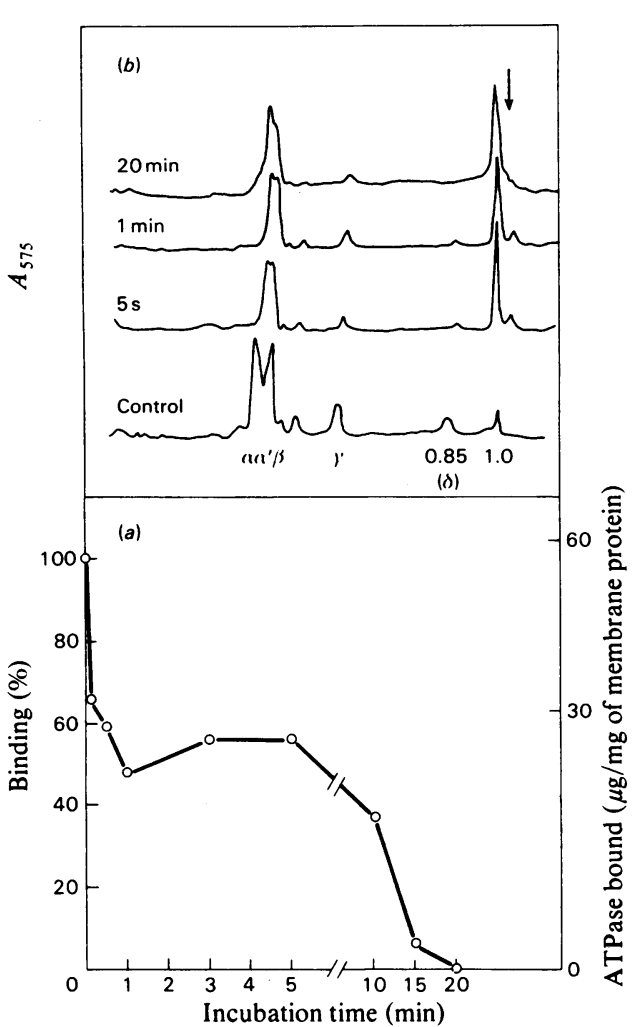

Fig. 5. Effect of trypsin on rebinding of M. lysodeikticus $B F_{1}$-ATPase (a) and analysis by SDS/10\%-acrylamidegel electrophoresis of the subunit modification induced by the proteinase $(b)$

For experimental details see the Materials and Methods section. Migration was from left to right $(+)$; arrow indicates the position of the tracking dye.

$5 b$ ). At the same time the $\gamma$ subunit underwent a similar degradation, also suggesting there is correlation between the defective binding of the ATPase and the destruction of that subunit. The plateau at $50 \%$ binding ability of the ATPase corresponded well to the residual amount of $\gamma$ subunit and 0.85relative-mobility component ( $\delta$ subunit), and the al- most total disappearance of this component correlated well with a $100 \%$ loss of ATPase reattachment, although $25 \%$ of the $\gamma$ subunit was left. This effect was accompanied by a limited degradation of the $\alpha$ subunit. These results show that the 0.85 -relative-mobility component ( $\delta$ subunit) of $M$. lysodeikticus ATPase is required for binding of the enzyme to the membrane. This result was confirmed by the isolation of an ATPase deficient in $\delta$ subunit by 20 min incubation of the enzyme with trypsin and subsequent micro-preparative gel electrophoresis (see the Materials and Methods section). The isolated protein, with subunit composition $\alpha_{3}^{\prime} \beta_{3} \gamma_{0.3}$, was unable to rebind to the membranes, i.e. less than $1 \%$ of the amount of ${ }^{125}$ I-labelled protein was found in the sediment after the binding assay. These results make less likely a role of the $\gamma$ subunit in ATPase binding to the membrane, although its role cannot be totally precluded. However, the necessity of intactness of the $\alpha$ subunit for the attachment of the ATPase to the membrane appears to be less significant. This notion was confirmed by experiments on ATPase binding by using enzyme preparations that have undergone a spontaneous degradation of $\alpha$ subunit and its transformation into the $\alpha^{\prime}$ form, to overlap with $\beta$ subunits in 7\%-acrylamide/SDS gels (see the Materials and Methods section). These preparations showed the same $50 \%$ efficiency in rebinding.

It is worth noting that similar results were obtained in binding experiments irrespective of the technique used.

\section{Discussion}

The homologies of $F_{1}$ factors from different origins (mitochondria, chloroplasts and bacteria) have been demonstrated (see Pedersen, 1975, for a review). A detailed exploration of the structural differences between these proteins in connection with the functional diversity of the energy-transducing machineries appears to be worthwhile for an understanding of their structure-function relationship. In this regard, Micrococcus lysodeikticus BF $_{1}$ ATPase seems to be an interesting model. It belongs to the energy-transducing membrane complex of a strict 
Table 3. Sensitivity to trypsin of the subunits of Micrococcus lysodeikticus $B F_{1}$ factor in relation to rebinding of ATPase to the membrane

Samples containing $60 \mu \mathrm{g}$ of ATPase were treated with trypsin $(4 \mu \mathrm{g})$ for $5 \mathrm{~s}$ or $20 \mathrm{~min}$ as described in the Materials and Methods section and subsequently analysed by electrophoresis in SDS/10\% acrylamide gels (Fig. 5). The areas of the subunits were calculated from the densitometric scans of the gels stained with Coomassie Blue R-250 and were correlated with the ability of the treated samples to rebind to the membranes.

\begin{tabular}{ccccc} 
& ATPase rebinding & \multicolumn{3}{c}{ Subunit area (\% of zero-time value) } \\
\cline { 3 - 5 } Trypsin treatment & $(\%)$ & $\alpha+\beta$ & $\gamma$ & $\delta$ \\
0 & 100 & 100 & 100 & 100 \\
$5 \mathrm{~s}$ & 50 & 76.5 & 54.1 & 57.8 \\
$20 \mathrm{~min}$ & 0 & 71.05 & 23.3 & 0.0
\end{tabular}

aerobe and possesses a subunit pattern of intermediate complexity between that of five-subunit ATPases (mitochondria, chloroplasts, $S$. faecalis and $E$. coli) and that of ATPases from other aerobic bacteria, which are apparently made up of two subunits. The quaternary structure of purified $M$. lysodeikticus $\mathrm{BF}_{1}$ factor (Andreu et al., 1973; Andreu \& Muñoz, 1975) was shown to consist of three welldefined subunits, referred to as $\alpha, \beta$ and $\gamma$ on the basis of their molecular weights. Trypsin was unable to stimulate the purified enzyme (Andreu et al., 1973), which correlated well with the absence of a subunit $(\varepsilon)$ in the $10000-12000$-mol.wt. range. A subunit of this kind appears to be the natural inhibitor of ATPase from mitochondria (Penefsky, 1974), chloroplasts (Nelson, 1976) and E. coli (Smith \& Sternweis, 1975). Moreover, it had been suggested from previous work that the natural inhibitor of $\boldsymbol{M}$. lysodeikticus ATPase was a polypeptide of about 25000 mol.wt. that readily dissociated from the $\mathrm{BF}_{1}$ complex (Carreira et al., 1976b). In the present work, a new polypeptide component of $M$. lysodeikticus $\mathrm{BF}_{1}$ factor has been identified. This polypeptide, whose molecular weight is similar to that of the $\delta$ subunit of other $F_{1}$-factor systems (Pedersen, 1975; Nelson, 1976; Bragg \& Hou, 1975), may also be considered equivalent to the $\delta$ subunit on account of its functional role (see below). This result then extends the similarities between different ATPase systems, but raises questions about the significance of associated polypeptides as ATPase subunits and their dependence on the isolation procedure. Further work is required to answer these questions. Preliminary evidence suggests that the association of this $\delta$-like subunit with $M$. lysodeikticus $\mathrm{BF}_{1}$ factor depends on bivalent cations (F. Mollinedo, unpublished work).

The subunits of $M$. lysodeikticus $\mathrm{BF}_{1}$ factor could not be dissociated unless fully denaturing conditions were employed (Nieto et al., 1975; Andreu \& Muñoz, 1979). These characteristics have hampered reconstitution studies of $M$. lysodeikticus $\mathrm{BF}_{1}$, aimed at defining the role of each subunit (Andreu \& Muñoz, 1979). Therefore we approached the prob- lem indirectly. The combined use of trypsin digestion and specific antibodies. has provided evidence to support the notion that the $\beta$ subunit is essential for the ATP-hydrolytic acitivity of $M$. lysodeikticus $\mathrm{BF}_{1}$ factor, although this subunit requires a minor proportion of $\alpha$ subunit, i.e. 1 molecule of $\alpha$ per 3 molecules of $\beta$, to be active. A similar conclusion has been reached for the ATPase of Micrococcus A.T.C.C. 398 (Höckel et al., 1976).

The present paper provides evidence to support the role of the minor subunits in the binding of $M$. lysodeikticus $\mathrm{BF}_{1}$ factor to the membranes, which seems to be a general property of all $F_{1}$-factor systems studied (Sternweis \& Smith, 1977; Abrams et al., 1976a; Nelson \& Karny, 1976). At the same time, the present study does not support the notion that the $\alpha$ subunit or any of its fragments plays a role in the binding of $M$. lysodeikticus $\mathrm{BF}_{1}$ factor to the membrane, therefore confirming the earlier observation by Salton \& Schor (1972). These results are unlike those reported by Abrams et al. $(1975,1976 b)$ on $S$. faecalis ATPase and by Bragg \& Hou (1978) on $E$. coli ATPase. The reasons for this difference are not known at present, but it is tempting to think that an answer to this question will arise from careful sequence studies of the fragments responsible for ATPase binding.

The identification of the $\delta$ polypeptide component in $M$. lysodeikticus $\mathrm{BF}_{1}$ factor was crucial in understanding attachment of ATPase to the membrane. In the light of these findings, which extend the existence and role of $\delta$ subunits in the $F_{1}$-factor system, it is worth noting that a study of the binding properties of B. megaterium and B. subtilis ATPases would be extremely rewarding, since these enzymes possess only $\alpha$ and $\beta$ subunits (Serrahima-Zieger \& Monteil, 1978). The fact that $50 \%$ of the ATPase molecules present in our assays were able to bind to the membranes suggests that half of the enzyme molecules lacked some components that ensure the association of the ATPase with the membrane and were therefore deficient in $\delta$ or $\gamma$ subunits.

On the other hand, the possibility arises from the present studies that the $\gamma$ subunit also plays a role in 
the binding of ATPase to the membrane. It may be suggested that $\gamma$ subunit is required for the attachment of $\delta$ subunit to the ATPase complex, or that more than one $\gamma$ subunit per molecule of ATPase (see above) is necessary for the proper binding. In any case, this is the first report where a possible role of a $\gamma$ subunit in ATPase binding to the membrane is suggested. Structural-functional roles for the $\gamma$ subunit in ATP hydrolysis and synthesis have been suggested in $\mathrm{F}_{1}$-ATPases of chloroplasts (Nelson, 1976) and $E$. coli (Futai, 1977; Larson \& Smith, 1977).

The immunological studies carried out in the present work extend those performed earlier by Whiteside \& Salton (1970). These authors demonstrated that anti-ATPase antibodies completely inhibited the ATPase activity non-competitively, also suggesting that the antiserum was acting on sites adjacent to the catalytic site and inducing conformational changes. This may explain the present results, showing low efficiency of anti-subunit antibodies to inhibit ATPase activity, though the relatively stronger effect of anti-( $\beta$-subunit) serum supports the view that this subunit contains the catalytic site of $M$. lysodeikticus ATPase. Antisera were tested for their ability to inhibit ATPase binding to membranes. All antisera inhibited the binding to a small extent, the major perturbation being induced by anti- $(\gamma$-subunit) and anti-( $\beta$-subunit) sera. The lack of conclusive results is not surprising in view of the role played by the $\delta$ subunits in this property of the ATPase, which should be taken into account in future immunological approaches to this problem.

In summary, this work has allowed us to advance our understanding of the structural-functional relationship of $M$. lysodeikticus ATPase and represents the first work of this kind performed on a $\mathrm{BF}_{1}$ enzyme from an aerobic bacterium.

We are indebted to Professor E. Racker (Cornell University, New York) for discussion and helpful criticism of the manuscript. The work was supported by a grant from Fondo Nacional para el Desarrollo de la Investigacion (E. M.) and by a fellowship from the Instituto Nacional para Asistencia y Promoción del Estudiante (F. M.).

\section{References}

Abrams, A., Jensen, C. \& Morris, D. (1975) J. Supramol. Struct. 3, 261-274

Abrams, A., Jensen, C. \& Morris, D. (1976a) Biochem. Biophys. Res. Commun. 69, 804-811

Abrams, A., Morris, D. \& Jensen, C. (1976b) Biochemistry 15, 5560-5566

Andreu, J. M. \& Muñoz, E. (1975) Biochim. Biophys. Acta 387, 228-233

Andreu, J. M. \& Muñoz, E. (1979) Biochemistry 18, 1836-1844

Andreu, J. M., Albendea, J. A. \& Muñoz, E. (1973) Eur. J. Biochem. 7, 490-501
Andreu, J. M., Carreira, J. \& Muñoz, E. (1976) FEBS Lett. 65, 198-203

Bragg, P. D. \& Hou, C. (1975) Arch. Biochem. Biophys. 167, 311-321

Bragg, P. D. \& Hou, C. (1978) Can. J. Biochem. 56, 559-564

Brody, S. \& Carlstrom, E. (1961) Nature (London) 189, 841-842

Campbell, D. H., Garvey, J. S., Cremer, N. E. \& Sussdorf, D. H. (1964) Methods in Immunology, pp. 118-120, W. A. Benjamin, New York

Carreira, J., Andreu, J. M., Nieto, M. \& Muñoz, E. (1976a) Mol. Cell. Biochem. 10, 67-76

Carreira, J., Muñoz, E., Andreu, J. M. \& Nieto, M. (1976b) Biochim. Biophys. Acta 436, 183-189

Carreira, J., Andreu, J. M. \& Muñoz, E. (1977) Biochim. Biophys. Acta 492, 387-398

Clausen, J. (1969) Immunochemical Techniques for the Identification and Estimation of Macromolecules, $\mathrm{pp}$. 454-465, North-Holland/American Elsevier, Amsterdam, Oxford and New York

Deters, D. W., Racker, E., Nelson, N. \& Nelson, H. (1975) J. Biol. Chem. 250, 1041-1047

Dietzel, W., Kopperschlager, C. \& Hoffman, E. (1972) Anal. Biochem. 48, 617-620

Fairbanks, G., Steck, T. L. \& Wallach, D. F. H. (1971) Biochemistry 10, 2606-2617

Futai, M. (1977) Biochem. Biophys. Res. Commun. 79, 1231-1237

Höckel, M., Hulla, F. W., Risi, S. \& Dose, K. (1976) Biochim. Biophys. Acta 429, 1020-1028

Kanner, B. I., Nelson, N. \& Gutnick, D. L. (1975) Biochim. Biophys. Acta 396, 347-359

Kozlov, I. A. \& Skulachev, V. P. (1977) Biochim. Biophys. Acta 463, 29-89

Larraga, V. \& Muñoz, E. (1975) Eur. J. Biochem. 54, 207-218

Larson, R. J. \& Smith, J. B. (1977) Biochemistry 16, 4266-4270

Lowry, O. H., Rosebrough, N. J., Farr, A. L. \& Randall, R. J. (1951) J. Biol. Chem. 193, 265-275

Mirsky, R. \& Barlow, V. (1973) Biochim. Biophys. Acta 291. 480-488

Muñoz, E., Freer, J. H., Ellar, D. J. \& Salton, M. R. J. (1968a) Biochim. Biophys. Acta 150, 531-533

Muñoz, E., Nachbar, M. S., Schor, M. T. \& Salton, M. R. J. (1968b) Biochem. Biophys. Res. Commun. 32, 539-546

Muñoz, E., Salton, M. R. J., Ng, M. H. \& Schor, M. T. (1969) Eur. J. Biochem. 7, 490-501

Nelson, N. (1976) Biochim. Biophys. Acta 456, 314-338

Nelson, N. \& Karny, O. (1976) FEBS Lett. 70, 249 253

Nelson, N., Deters, D. W., Nelson, H. \& Racker, E. (1973) J. Biol. Chem. 248, 2049-2055

Nelson, N., Kanner, B. I. \& Gutnick, D. L. (1974) Proc. Natl. Acad. Sci. U.S.A. 71, 2720-2724

Nieto, M., Muñoz, E., Carreira, J. \& Andreu, J. M. (1975) Biochim. Biophys. Acta 413, 394-414

Pedersen, P. L. (1975) J. Bioenerg. 6, 243-275

Penefsky, H. S. (1974) Enzymes 3rd Ed. 10, 375-394

Salton, M. R. J. \& Schor, M. T. (1972) Biochem. Biophys. Res. Commun. 49, 350-357

Senior, A. (1973) Biochim. Biophys. Acta 301, 249-277 
Serrahima-Zieger, M. \& Monteil, H. (1978) Biochim. Biophys. Acta 502, 445-457

Smith, J. B. \& Sternweis, P. C. (1975) Biochem. Biophys. Res. Commun. 62, 764-771

Stark, G. R., Stein, W. H. \& Moore, S. (1960) J. Biol. Chem. 235, 3177-3181

Sternweis, P. C. (1978) J. Biol. Chem. 253, 3123-3128

Sternweis, P. C. \& Smith, J. B. (1977) Biochemistry 16, 4020-4025
Vogel, G. \& Steinhart, R. (1976) Biochemistry 15, 208216

Whiteside, T. L. \& Salton, M. R. J. (1970) Biochemistry 9, 3034-3040

Yoshida, M., Sone, N., Hirata, H. \& Kagawa, Y. (1975) J. Biol. Chem. 250, 7910-7916

Yoshida, M., Sone, N., Hirata, H. \& Kagawa, Y. (1977) J. Biol. Chem. 252, 3480-3485 